Resona Jumal Ilmiah Pengabdian Masyarakat Vol. 2, No. 1 (2018) 18-27

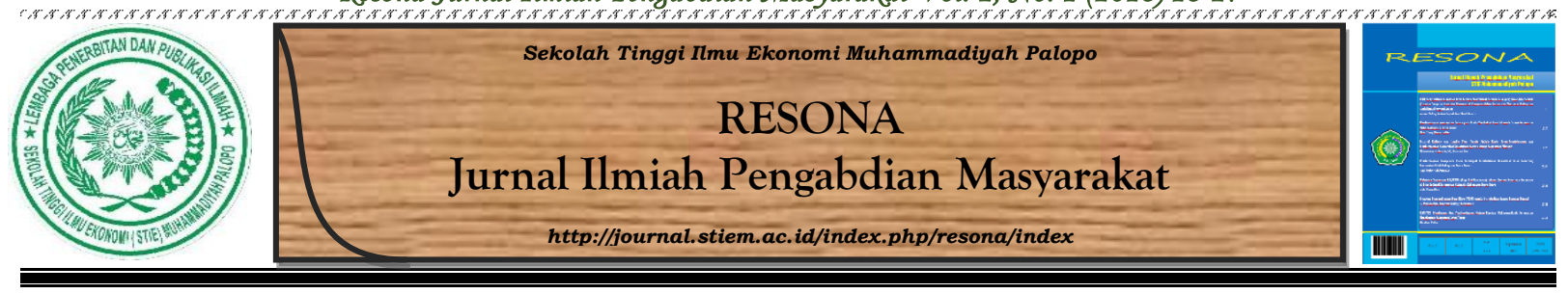

\title{
Festival Kuliner dan Lomba Foto Pesisir Kuliah Kerja Nyata-Pembelajaran dan Pemberdayaan Masyarakat Kecamatan Mattiro Sompe Kabupaten Pinrang
}

\author{
Muhammad Arhan Rajab ${ }^{1}$, Marwan Sam²
}

\section{${ }^{1,2}$ Universitas Cokroaminoto Palopo}

\section{INFO NASKAH}

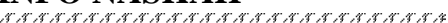
Diserahkan (mail)

31 Juli 2018

Diterima

7 Agustus 2018

Diterima dan disetujui

7 Agustus 2018

7. Agustus 2018 is

\section{Kata Kunci:}

Desa mattiro tasi

Festival kuliner

Lomba foto pesisir

Kecamatan mattiro sompe

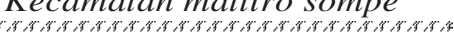

\begin{abstract}
ABSTRAK Pregram kerja ini bertujuan melakukan pengabdian kepada masyarakat Kecamatan Mattiro Sompe melalui Kuliah Kerja Nyata-Pembelajaran Pemberdayaan Masyarakat (KKN-PPM) dalam memanfaatkan sumber daya alam pesisir yang ada. Target khusus yang ingin dicapai pada kegiatan ini adalah peningkatan partisipasi masyarakat Desa Mattiro Tasi dalam kegiatan festival kuliner dan lomba foto pesisir. Metode yang digunakan dalam pelaksanaan kegiatan ini terbagi dua tahapan, yaitu persiapan dan pelaksanaan. Persiapan meliputi observasi tempat, penentuan waktu dan tempat, mengundang masyarakat, sosialisasi kepada masyarakat tentang gambaran kegiatan dan pengadaan perlengkapan yang akan digunakan dalam kegiatan, sedangkan pelaksanaan diawali dengan registrasi ulang peserta, pembukaan kegiatan, penyajian makanan oleh masing-masing tim, pameran foto pesisir, penilaian makanan oleh tim juri sedangkan penilaian foto oleh pengunjung Pantai Harapan Ammani. Pengumuman pemenang untuk masing-masing lomba dilanjutkan dengan penyerahan hadiah kepada masing-masing pemenang festival kuliner dan lomba foto pesisir. Berdasarkan hasil dari pelaksanaan kegiatan festival kuliner dan lomba foto pesisir, masyarakat telah mampu membuat olahan makanan laut yang beragam yang tentunya mampu menginspirasi masyarakat lainnya. Selain itu, melalui kegiatan lomba foto pesisir, masyarakat mampu memperkenalkan wisata Pantai Harapan Ammani Desa Mattiro Tasi Kecamatan Mattiro Sompe Kabupaten Pinrang kepada para pengunjung.
\end{abstract}

\section{Pendahuluan}

Kegiatan Kuliah Kerja Nyata (KKN) merupakan kegiatan lapangan bagi mahasiswa yang menempuh bagian akhir dari program S-1. Kuliah Kerja Nyata Pembelajaran Pemberdayaan Masyarakat yang selanjutnya disingkat KKN-PPM merupakan kegiatan kurikuler bagi mahasiswa dengan terjun langsung di masyarakat. KKN-PPM adalah suatu bentuk pendidikan 
dengan cara memberikan pengalaman belajar kepada mahasiswa untuk hidup di tengah-tengah masyarakat di luar kampus dan secara langsung mengidentifikasi serta menangani masalahmasalah yang terjadi di masyarakat. KKN-PPM dimaksud untuk meningkatkan relevansi pendidikan tinggi dengan perkembangan dan kebutuhan masyarakat akan ilmu pengetahuan, teknologi serta seni untuk melaksanakan pembangunan yang makin pesat serta meningkatkan persepsi mahasiswa tentang relevansi antara materi kurikulum yang mereka pelajari di kampus dengan realitas pembangunan dalam masyarakat.

Adanya program KKN-PPM dapat meningkatkan kedewasaan dan profesionalisme mahasiswa serta sebagai cara untuk meningkatkan kesejahteraan dan mengembangkan potensi masyarakat melalui pemberdayaan. Pengalaman lain yang didapat oleh mahasiswa adalah saat menghadapi kehidupan masyarakat sebenarnya, memahami pola pikir masyarakat yang bervariasi. Sebagai salah satu bagian dari mahasiswa yang melakukan kegiatan KKN-PPM, menjadi sebuah kewajiban bagi kami untuk menyusun laporan kegiatan selama KKN-PPM dilaksanakan.

Adapun tempat pelaksanaan KKN-PPM mahasiswa Universitas Cokroaminoto Palopo adalah di desa Mattiro Tasi, Kecamatan Mattiro Sompe, Kabupaten Pinrang. Kawasan Kabupaten Pinrang merupakan salah satu lokasi kegiatan Pengembangan Desa Pesisir Tangguh (PDPT) pada tahun 2012-2014 yang berlokasi di 1 (satu) desa dan 2 (dua) kelurahan yang terdapat di 1 (satu) kecamatan, diantaranya Desa Mattiro Tasi, Kelurahan Langnga dan Kelurahan Pallameang. Ketiga lokasi tersebut berada di Kecamatan Mattiro Sompe. Desa Mattiro Tasi merupakan salah satu desa yang terdapat di Kecamatan Mattiro Sompe yang mempunyai luas wilayah seluas $\pm 1471,41$ hektar. Tanah di Desa Mattiro Tasi sebagian besar diperuntukkan untuk tanah tani tambak, pertanian sawah, peternakan, nelayan dan lain-lain. Sedangkan sisanya untuk tanah kering yang merupakan bangunan dan fasilitas-fasilitas lainnya.

Desa Mattiro Tasi mempunyai jumlah penduduk sebanyak 1632 jiwa yang tersebar dalam 3 (tiga) dusun dalam wilayah Desa Mattiro Tasi, diantaranya Dusun Ammani Selatan, Dusun Ammani Utara dan Dusun Manni Sawa. Kondisi alam Desa Mattiro Tasi terdiri dari dataran dengan luas $3750 \mathrm{~m}^{2}$. Desa ini merupakan salah satu desa yang ada di Kabupaten Pinrang yang terletak di pinggiran pesisir pantai. Pengaruh keadaan alam yang berupa dataran dan berada di pinggir pantai mengakibatkan mata pencaharian penduduknya yang berbeda-beda, namun yang paling mendominasi adalah bekerja sebagai petani dan nelayan. 
Tujuan dari kegiatan festival kuliner dan lomba foto pesisir ini, disamping untuk memanfaatkan sumber daya alam pesisir terutama dalam bidang pertanian khususnya perikanan di daerah Mattiro Tasi juga untuk meningkatkan kreativitas masyarakat dalam membuat olahan makanan laut. Selain itu kegiatan ini juga bertujuan memperkenalkan wisata Pantai Harapan Ammani kepada masyarakat luar yang berkunjung untuk meningkatkan jumlah pengunjung setiap tahunnya melalui pameran foto pesisir.

\section{Permasalahan Mitra}

Masalah yang dihadapi masyarakat di Desa Mattiro Tasi Kecamatan Mattiro Sompe adalah kurangnya pengetahuan pengelolaan dan pemanfaatan sumber daya laut bagi masyarakat serta kurangnya kreativitas masyarakat dalam mengolah hasil laut menjadi menu makanan sehat sehingga sumber daya yang tersedia di alam tidak terolah semaksimal mungkin. Oleh karena itu, dengan diadakannya festival kuliner penulis berharap hal ini dapat memicu kreativitas masyarakat pesisir dalam mengelola hasil laut. Demikian pula dengan pesona alam yang terdapat di Desa Mattiro Tasi tidak terekspos oleh dunia luar sehingga para pelancong (turis) tidak mengetahui bahwa pemandangan pantai di Desa Mattiro Tasi sangatlah indah. Diharapkan dari kegiatan lomba foto dapat memicu kesadaran warga untuk mengelola lokasi yang ada menjadi objek wisata sehingga dapat meningkatkan pendapatan masyarakat dan pemerintah setempat.

\section{Metode Pelaksanaan}

Program Kuliah Kerja Nyata-Pembelajaran Pemberdayaan Masyarakat (KKN-PPM) mahasiswa Universitas Cokroaminoto Palopo di Desa Mattiro Tasi Kecamatan Mattiro Sompe Kabupaten Pinrang yaitu festival kuliner dan lomba foto pesisir se-Kecamatan Mattiro Sompe dilaksanakan dalam 2 tahapan yaitu:

\section{Tahap Persiapan}

Pada tahapan ini, mahasiswa KKN-PPM melakukan beberapa kegiatan meliputi:

a. Observasi awal ke lokasi kegiatan dengan melihat keadaan masyarakat yang ada di wilayah tersebut kemudian mendatangi kantor Desa Mattiro Tasi Kecamatan Mattiro Sompe untuk menyampaikan program kerja yang akan dilaksanakan sekaligus meminta izin kepada Bapak Kepala Desa Mattiro Tasi untuk melaksanakan kegiatan tersebut. Kemudian melakukan tinjauan langsung ke Pantai Harapan Ammani untuk mengamati lokasi tempat kegiatan. 
b. Mahasiswa KKN-PPM melakukan musyawarah untuk menentukan waktu dan tempat kegiatan dilaksanakan nantinya dengan bantuan arahan Kepala Desa Mattiro Tasi dan Kepala Pengelola wisata Pantai Harapan Ammani.

c. Mengadakan surat permohonan peserta kegiatan kepada seluruh Kelurahan dan Desa yang ada dalam lingkup Kecamatan Mattiro Sompe.

d. Mahasiswa KKN-PPM melakukan sosialisasi tentang kegiatan program kerja yang akan dilaksanakan dengan memberikan gambaran tentang kegiatan festival kuliner dan lomba foto pesisir dan mengajak masyarakat untuk ikut berpartisipasi dalam kegiatan tersebut. Selain sosialisasi secara langsung, juga dilaksanakan sosialisasi secara tidak langsung yaitu mengadakan pamflet kegiatan di setiap desa dan semua kelurahan yang ada dalam lingkup Kecamatan Mattiro Sompe sebagai media informasi.

e. Menyiapkan perlengkapan yang akan digunakan dalam kegiatan festival kuliner dan lomba foto pesisir tersebut yang meliputi pembuatan dua lembar spanduk sebagai media informasi, pemasangan tenda, kursi, meja, dan sound system.

\section{Tahap Pelaksanaan}

Mahasiswan KKN-PPM dalam tahap ini melakukan beberapa kegiatan sebagai berikut:

a. Registrasi ulang bagi peserta festival kuliner dan lomba foto pesisir.

b. Pembukaan kegiatan festival kuliner dan lomba foto pesisir yang dihadiri oleh pihak Kecamatan Mattiro Sompe, aparat Desa Mattiro Tasi, tokoh-tokoh masyarakat dalam lingkup Desa Mattiro Tasi serta masyarakat yang menjadi peserta dalam festival kuliner dan lomba foto pesisir. Kegiatan ini dibuka langsung oleh koordinator ketenagakerjaan Kecamatan Mattiro Sompe.

c. Persiapan tempat festival kuliner dan lomba foto pesisir

d. Penyajian dan presentasi makanan yang telah disiapkan oleh peserta festival kuliner dilanjutkan dengan tahap penilaian oleh tim juri dan penilaian foto pesisir oleh pengunjung Pantai Harapan Ammani desa Mattiro Tasi.

e. Pengumuman pemenang festival kuliner dan lomba foto pesisir dilanjutkan dengan penyerahan hadiah kepada masing-masing pemenang.

\section{Hasil dan Pembahasan}

Hasil program kerja Kuliah Kerja Nyata-Pembelajaran Pemberdayaan Masyarakat (KKNPPM) dalam kegiatan festival kuliner dan lomba foto pesisir yang diadakan di Desa Mattiro 
Tasi Kecamatan Mattiro Sompe adalah sebagai berikut:

a. Observasi yang telah dilakukan oleh mahasiswa KKN-PPM dengan mengamati keadaan masyarakat di sekitar pesisir pantai dan bertemu langsung dengan Kepala Desa Mattiro Tasi dan Kepala Pengelolah Pantai Harapan Ammani yang bertujuan untuk menyampaikan ide kegiatan, permohonan rekomendasi kegiatan, penentuan waktu dan tempat pelaksanaan kegiatan festival kuliner dan lomba foto pesisir dengan arahan Kepala Pengelolah Pantai Harapan Ammani.

b. Pelaksanaan kegiatan Festival Kuliner di Aula Pantai Harapan Ammani Desa Mattiro Tasi sudah terlaksana sesuai dengan perencanaan yang diikuti oleh 3 (tiga) tim yang berasal dari Desa dan Kelurahan yang ada di Kecamatan Mattiro Sompe dengan menyajikan masingmasing 3 (tiga) jenis makanan olahan laut yang berbeda. Peserta dalam kegiatan ini terdiri dari tiga orang dalam setiap tim dengan masing-masing tim menyiapkan tiga jenis olahan makanan laut yang berbeda. Adapun kategori dalam penilaian kuliner tersebut adalah penilaian cara penyajian makanan, rasa masakan dan presentasi tentang olahan makanan tersebut.

c. Lomba foto pesisir yang diikuti oleh masyarakat se-Kecamatan Mattiro Sompe terlaksana sesuai dengan perencanaan. Kegiatan ini diawali dengan pameran foto pesisir yang telah diserahkan oleh masing-masing peserta. Kemudian dilanjutkan dengan tahap penilaian oleh pengunjung Pantai Harapan Ammani dengan memilih satu foto terbaik dari semua foto yang dipajang. Adapun mekanisme pemilihan foto tersebut adalah menulis nomor urut foto yang dipilih kemudian memasukkan hasil pilihan tersebut dalam kotak penilaian yang telah disediakan oleh mahasiswa.

d. Pengumuman pemenang untuk masing-masing kegiatan yaitu festival kuliner dan lomba foto pesisir disampaikan setelah tahap penilaian oleh tim juri. Adapun juara untuk festival kuliner berturut-turut adalah sebagai berikut:

1) Juara 1 oleh tim Diana (Pantai Ammani Baru) dengan makanan yang disajikan berupa tumis cumi hitam, masak mandar ikan cakalang, dan sambal ikan seribu.

2) Juara 2 oleh tim Ernawati (Ammani Selatan) dengan makanan yang disajikan berupa cumi isi nasi goreng, pacco khas Ammani, dan ikan goreng.

3) Juara 3 oleh tim Hasni (Pantai Ammani Indah) dengan makanan yang disajikan berupa ikan kakap merah goreng tepung, sup tulang ikan, dan lawa'. 
Sedangkan pemenang untuk kategori lomba foto pesisir adalah berturut-turut diraih oleh Erna (Desa Mattiro Tasi) sebagai juara pertama, Ahmad Adean (Desa Patobong) sebagai juara kedua dan Bulkis (Desa Mattiro Tasi) sebagai juara ketiga.

Penyerahan hadiah kepada masing-masing pemenang kategori festival kuliner dan lomba foto pesisir diserahakan oleh koordinator camat kepada juara ketiga, sekretaris desa kepada juara kedua dan koordinator ketenagakerjaan Kecamatan Mattiro Sompe kepada juara pertama.

\section{Simpulan dan Saran}

Program mahasiswa Kuliah Kerja Nyata-Pembelajaran Pemberdayaan Masyarakat (KKNPPM) melalui festival kuliner dan lomba foto pesisir telah dilaksanakan di Aula Pantai Harapan Ammani Desa Mattiro Tasi, Kecamatan Mattiro Sompe, Kabupaten Pinrang pada hari rabu tanggal 25 Juli 2018. Peserta festival kuliner dan lomba foto pesisir diikuti oleh masyarakat dari kelurahan dan desa dalam lingkup Kecamatan Mattiro Sompe. Berdasarkan hasil dari pelaksanaan kegiatan festival kuliner dan lomba foto pesisir, masyarakat telah mampu membuat olahan makanan laut yang beragam yang tentunya mampu menginspirasi masyarakat lainnya. Selain itu, melalui kegiatan lomba foto pesisir, masyarakat mampu memperkenalkan wisata Pantai Harapan Ammani Desa Mattiro Tasi Kecamatan Mattiro Sompe, Kabupaten Pinrang kepada para pengunjung.

Harapan kami dengan adanya festival kuliner dan lomba foto pesisir kepada masyarakat khususnya daerah pesisir agar dapat memanfaatkan semaksimal mungkin sumber daya alam yang terdapat di Kecamatan Mattiro Sompe terutama dalam sektor pertanian bidang perikanan seperti melakukan inovasi dalam pengolahan makanan laut sehingga dapat memiliki nilai ekonomis yang cukup tinggi dan mampu bersaing di pasaran khususnya di masa MEA (Masyarakat Ekonomi ASEAN). Selain itu, kami juga merekomendasikan kepada masyarakat yang bermukim di wilayah pesisir agar mengembangkan potensi alam Kecamatan Mattiro Sompe khususnya di Desa Mattiro Tasi sehingga menjadi suatu upaya dalam memperkenalkan wisata Pantai Harapan Ammani dan bagi pihak pemerintah setempat diharapkan dapat memberikan dukungan dan upaya untuk menunjang pelaksanaan program ini.

\section{Ucapan Terima Kasih}

Penulis mengucapkan terima kasih kepada Direktorat Riset dan Pengabdian kepada Masyarakat Kementerian Riset, Teknologi dan Pendidikan Tinggi yang telah mendanai 
kegiatan Kuliah Kerja Nyata-Pembelajaran dan Pemberdayaan Masyarakat ini, dan terima kasih atas kerjasama mitra dalam kegiatan pengabdian ini yakni Bapak Camat Mattiro Sompe dan Bapak Kepala Desa Mattiro Tasi. Selain itu, tak lupa pula penulis mengucapkan terima kasih atas partisipasi dari warga Desa Mattiro Tasi serta kepada Mahasiswa KKN-PPM Kecamatan Mattiro Tasi yang telah meluangkan waktu, tenaga, pikiran, dan segala sumber daya yang dimiliki demi kelancaran kegiatan ini.

\section{Daftar Pustaka}

Budiharsono, S. 2001. Teknik Analisis Pembangunan wilayah Pesisir dan Lautan. Pradnya Paramita. Jakarta.

Dahuri, R., J. Rais., S.P. Ginting., dan M.J. Sitepu. 2001. Pengelolaan Sumber Daya Pesisir dan Lautan Secara Terpadu. Pradnya Paramita. Jakarta.

Romimohtarto dan Soemodjhardjo. 1998. Pengelolaan Terumbu Karang Berbasis Masyarakat. Djambatan. Jakarta.

Walhi. 2004. Pembangunan Wilayah Perspektif Ekonomi, Sosial, dan Lingkungan. LP3ES. Jakarta. 


\section{Lampiran}

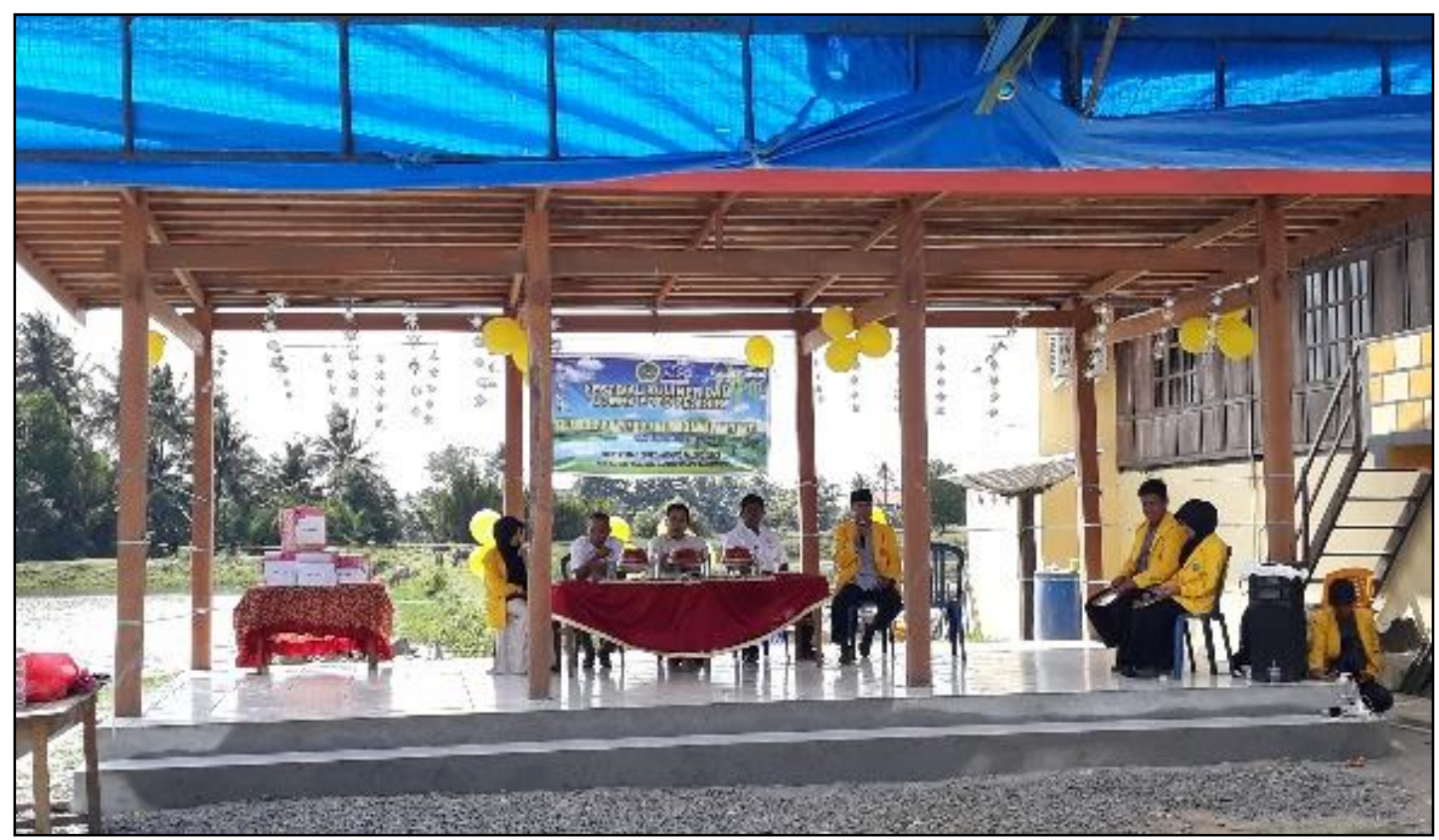

Gambar 1. Suasana pembukaan Festival Kuliner dan Lomba Foto

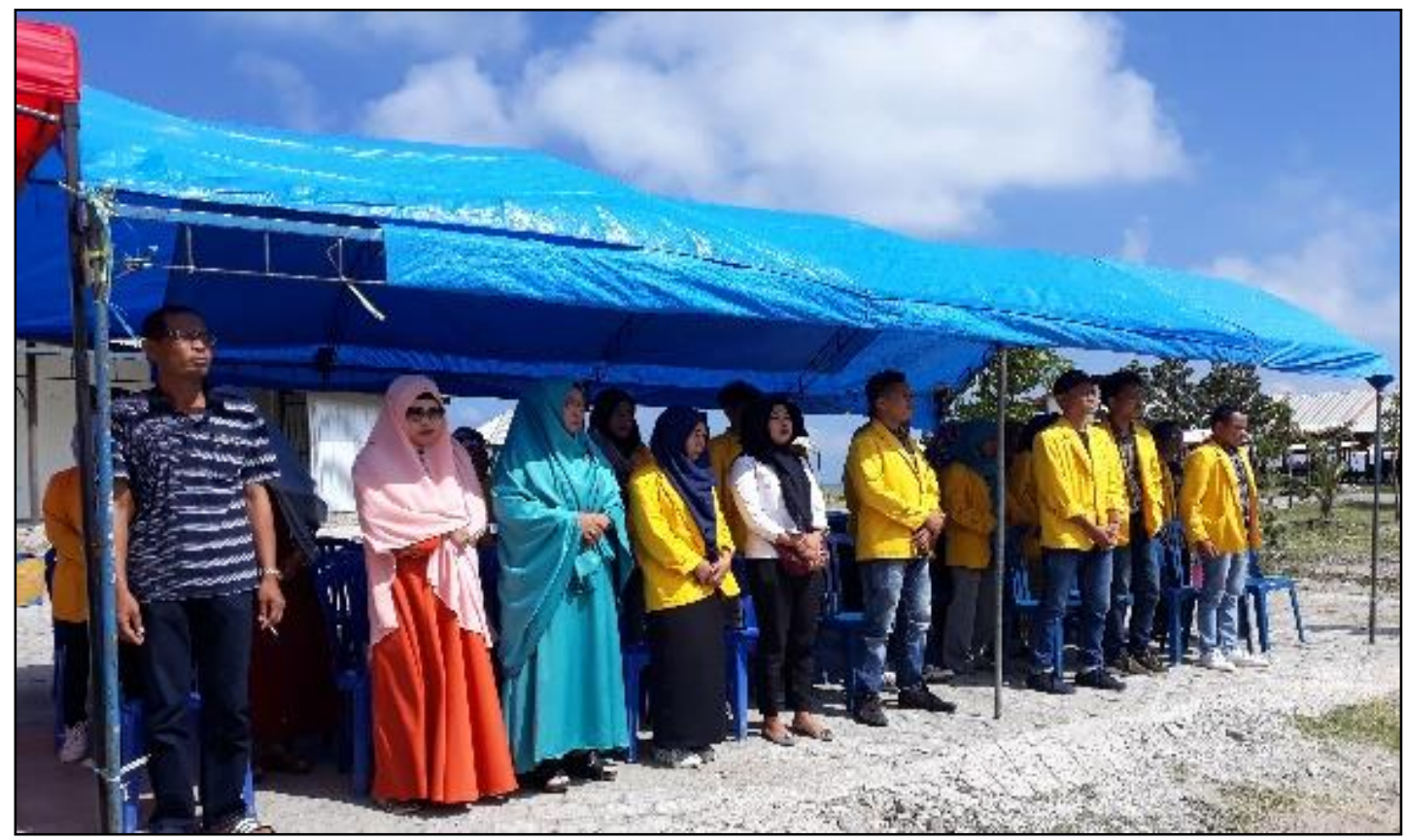

Gambar 2. Upacara Pembukaan Festival Kuliner dan Lomba Foto 
Resona Jurnal Ilmiah Pengabdian Masyarakat, 1 (2018): 18-27

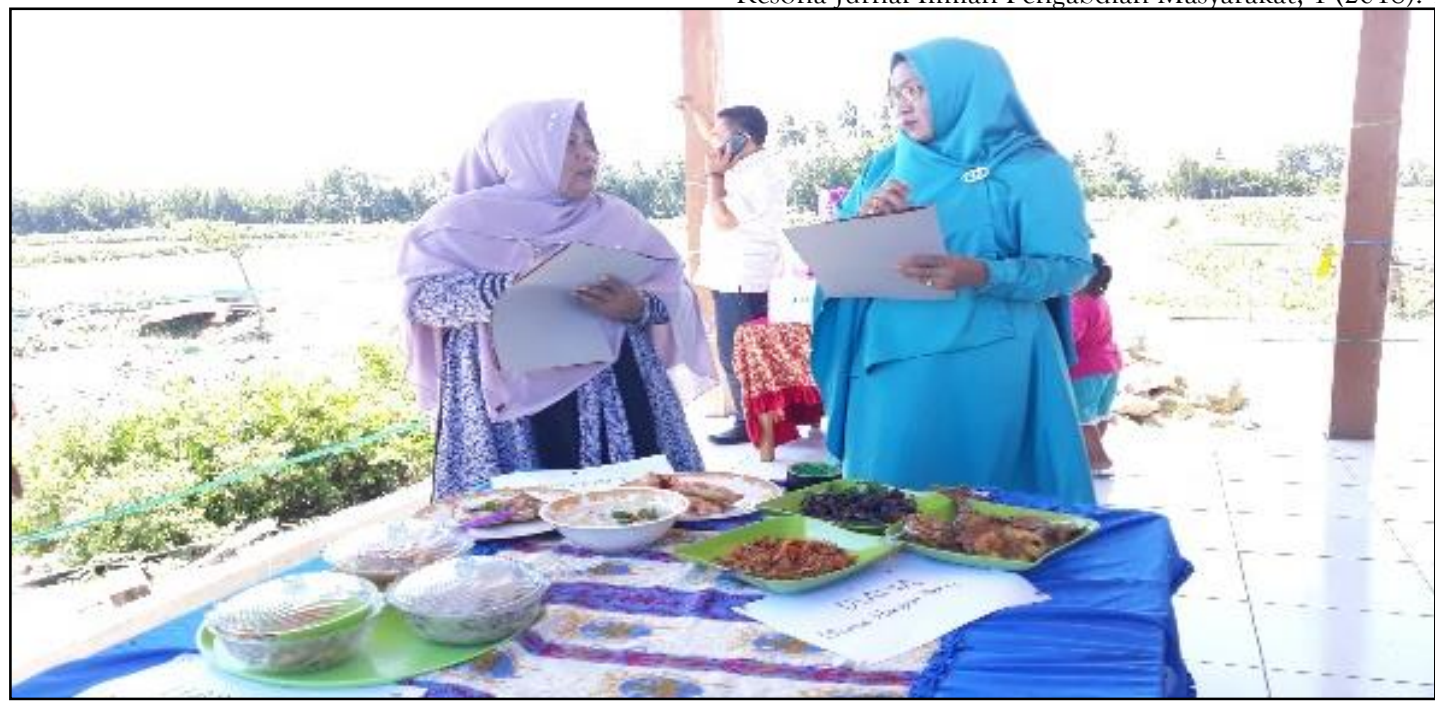

Gambar 3. Penilaian Makanan oleh Juri pada Festival Kuliner

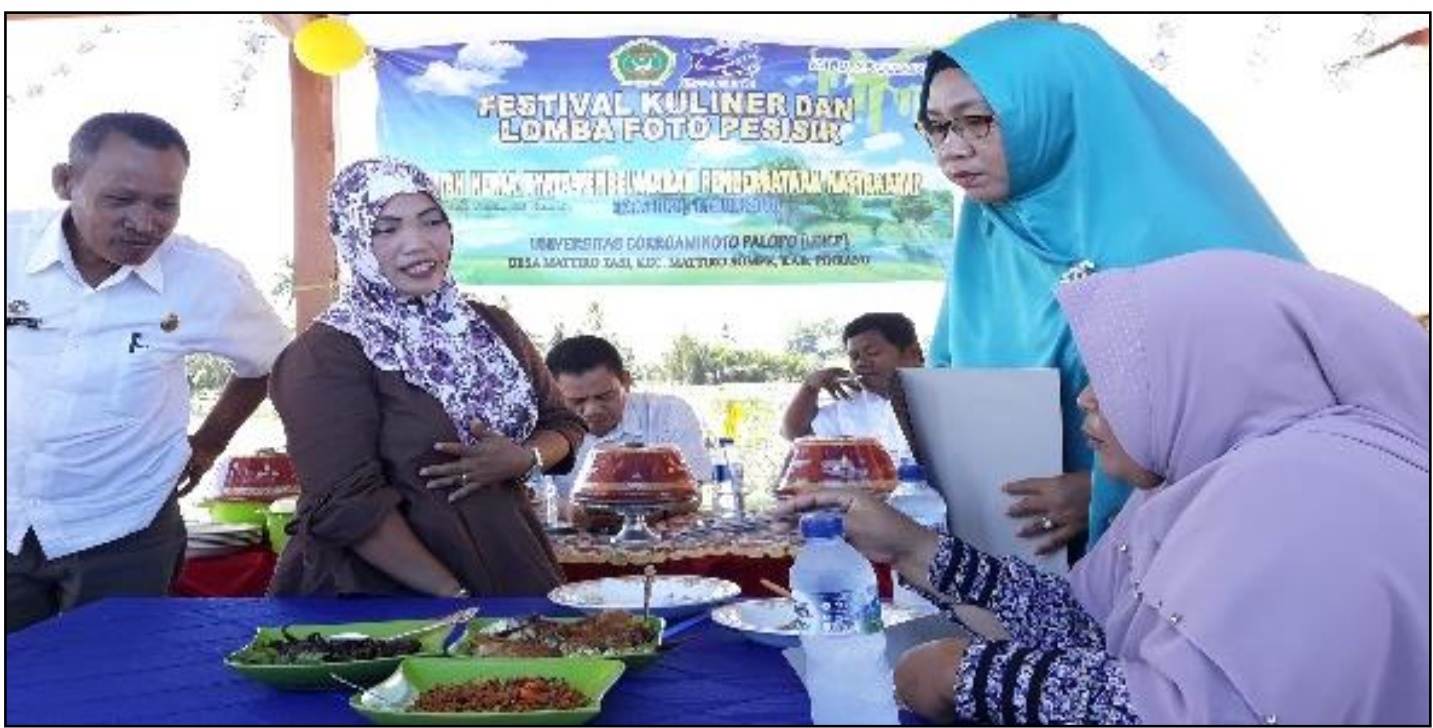

Gambar 4. Penilaian Makanan oleh Juri

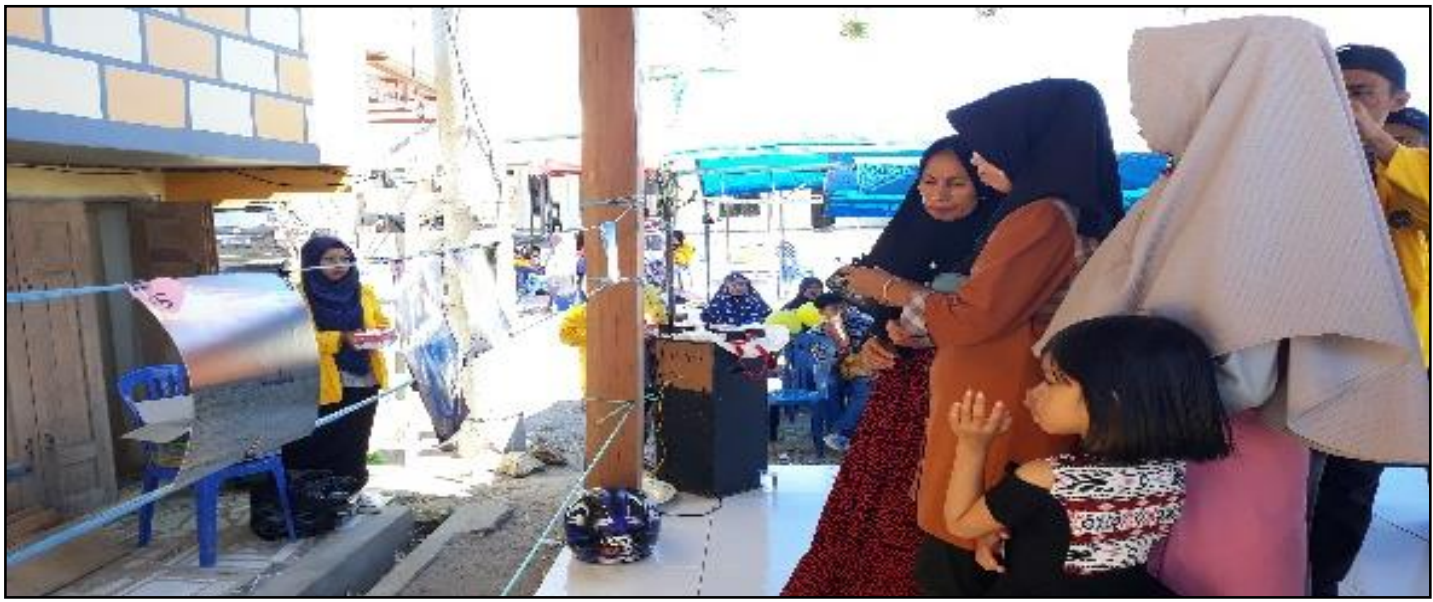

Gambar 5. Penilaian Lomba Foto oleh Para Pengunjung 


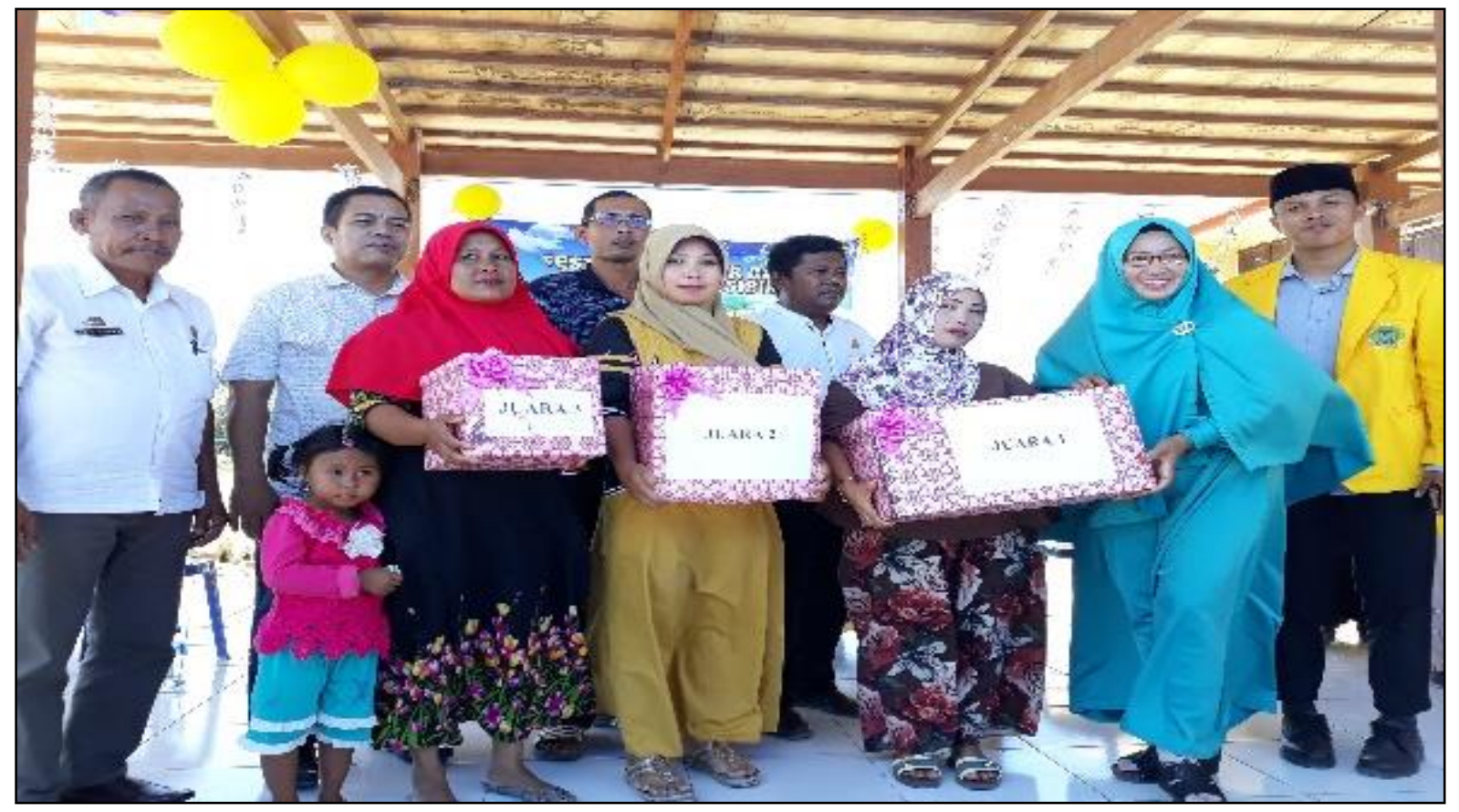

Gambar 6. Juara Pertama, Kedua dan Ketiga Lomba Festival Kunliner

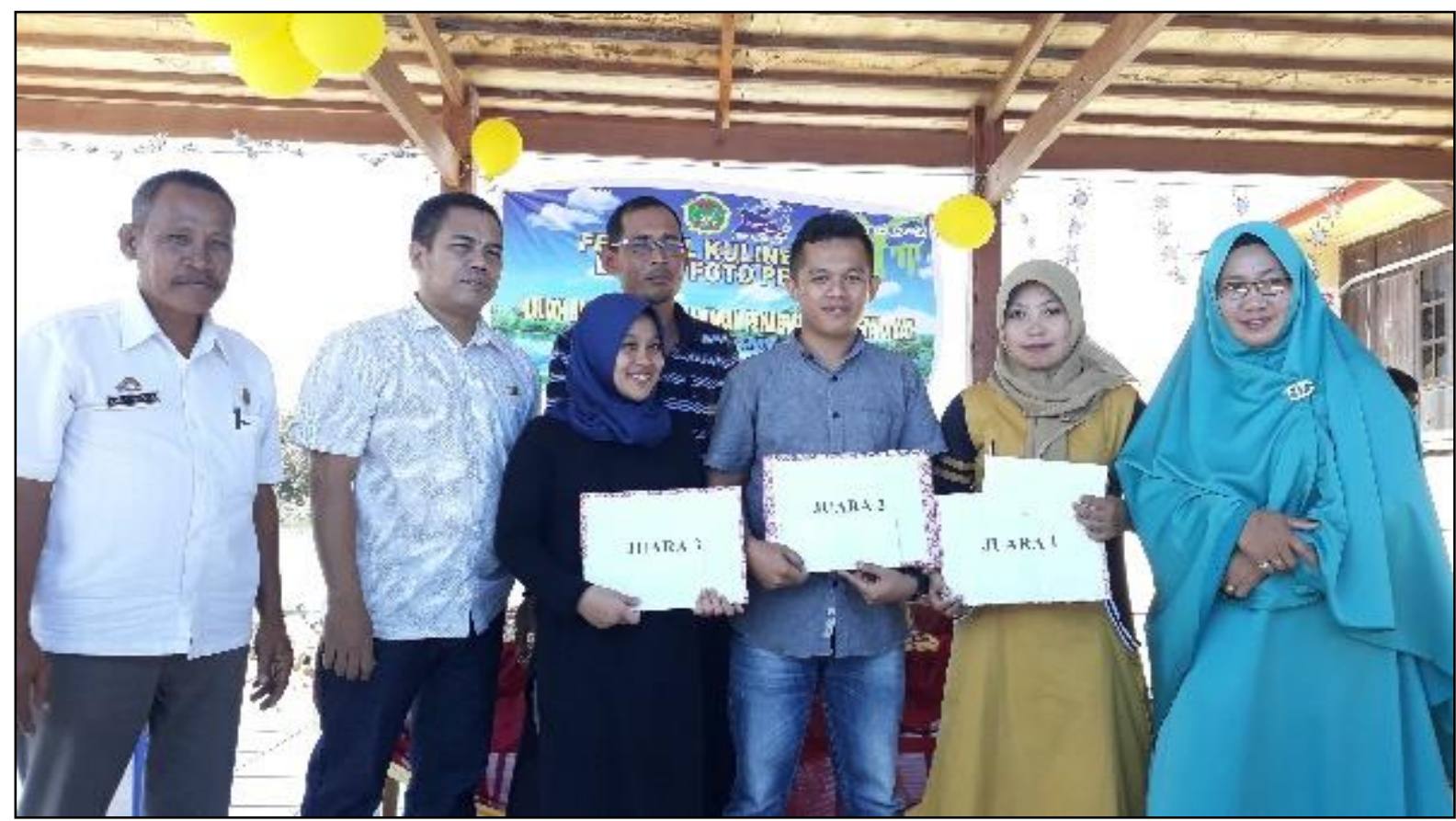

Gambar 7. Juara Pertama, Kedua dan Ketiga Lomba Foto Pesisir 